TẠP CHÍ KHOA HỌC ĐẠI HỌC TÂN TRÀO

ISSN: $2354-1431$

http://tckh.daihoctantrao.edu.vn/

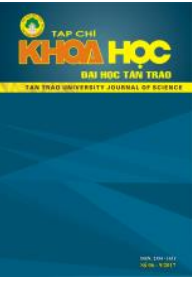

CARE, NUTRITION, AND ROUNDATION PROCESS DISEASE TREATMENT IN RI LAI CHICKEN AT NGUYEN QUANG CHINH, TRUNG MON COMMUNE, YEN SON DISTRICT, TUYEN QUANG PROVINCE

\author{
Nguyen Thi Hong Van ${ }^{1, *}$ \\ ${ }^{I}$ Tan Trao University, Vietnam \\ *Email address: hongvan90tq@gmail.com \\ http://doi.org/10.51453/2354-1431/2021/471
}

\section{Article info}

Recieved: $27 / 3 / 2021$

Accepted: 05/7/2021

\section{Keywords:}

Crossbred Ri chicken, growth, nurturing, prevention and treatment

\begin{abstract}
:
This process is carried out on the chicken farm of Nguyen Quang Chinh househoid, Trung Mon commune, Yen Son district, Tuyen Quang province. Research results have shown that the survival rate of Crossbred Ri chicken is quite high, with good adaptability to local natural conditions. Body weight of Crossbred $\mathrm{Ri}$ chicken at birth was $33.03 \mathrm{~g} / \mathrm{head}$; at 3 weeks old is 223.87 $\mathrm{g} / \mathrm{head}$, at 15 weeks old is $1807.62 \mathrm{~g} / \mathrm{head}$. The average absolute growth rate for the whole period was 16.90 (g/head/day), relative growth was 26.09 (g/head/day). In the process of raising chickens infected with E.coli, coccidiosis, CRD, the highest rate of chickens infected with coccidiosis was $1.73 \%$. When chickens are sick, use the drug after 5 days of symptoms of the disease in the disease in the chickens.
\end{abstract}


TẠP CHÍ KHOA HỌC ĐẠI HỌC TÂN TRÀO

ISSN: $2354-1431$

http://tckh.daihoctantrao.edu.vn/

\title{
QUY TRÌNH CHĂM SÓC, NUÔI DỮ̛̃NG, PHÒNG VÀ TRỊ BỆNH TRÊN ĐÀN GÀ RI LAI TẠI TRẠI NGUYẼ̃N QUANG CHÍNH, XÃ TRUNG MÔN, HUYỆN YÊN SƠN, TỈNH TUYÊN QUANG
}

\author{
Nguyễn Thị Hồng Vân ${ }^{l, *}$ \\ ${ }^{I}$ Truờng Đại học Tân Trào, Việt Nam \\ *Địa chi email: hongvan90tq@gmail.com \\ http://doi.org/10.51453/2354-1431/2021/471
}

\section{Thông tin bài viết}

Ngày nhận bài: 27/3/2021

Ngày duyệt đăng: 05/7/2021

\section{Từ khóa:}

Gà Ri Lai, sinh trương, dinh duõng, phòng và trị bệnh.

\section{Tóm tắt}

Quy trình này được thực hiện trên trại gà của hộ dân Nguyễn Quang Chính, xã Trung Môn, huyên Yên Sơn, tỉnh Tuyên Quang. Kết quả nghiên cứu đã chỉ ra rằng tỷ lệ nuôi sống gà Ri Lai khá cao, có khả năng thích nghi tốt với điều kiện tự nhiên của địa phương. Khối lượng cơ thể gà Ri Lai lúc sơ sinh là 33,03g/con; 3 tuần tuổi là $223,87 \mathrm{~g}, 15$ tuần tuổi là 1807,62g/con. Khả năng sinh trưởng tuyệt đối trung bình cả giai đoạn là 16,90 (g/con/ngày), sinh trưởng tương đối là 26,09 (g/con/ngày). Trong quá trình nuôi gà mắc bệnh $E$.coli, cầu trùng, $\mathrm{CRD}$ tỷ lệ gà mắc bệnh cầu trùng cao nhất $1,73 \%$. Gà bị bệnh dùng thuốc sau 5 ngày biểu hiện của bệnh trên đàn gà hết

\section{1. Đặt vấn đề}

Trong những năm gần đây, ngành chăn nuôi nước ta đã có những bước phát triển đáng kể cả về số lượng cũng như chất lượng, đặc biệt là chăn nuôi gia cầm do nhu cầu thực phẩm ngày càng tăng cao. Ước tính tổng số gia cầm của cả nước tháng 12 năm 2019 tăng 14,2 \% so với cùng thời điểm năm 2018; sản lượng thịt gia cầm hơi xuất chuồng cả năm ước đạt 1278,6 nghìn tấn, tăng 16,5\% so với năm 2018; sản lượng trứng gia cầm cả năm ước đạt 13,3 tỷ quả, tăng 14,0\% (Nguồn chăn nuôi Việt Nam, 2020) [5].

Khác hẳn với các ngành chăn nuôi khác, ngành chăn nuôi gia cầm của nước ta luôn được thị trường nội địa ưu ái nhờ những đặc trưng riêng của từng giống gà, hiện nay gà $\mathrm{Ri}$ Lai là giống gà được người chăn nuôi lựa chọn, đây là giống gà tạo ra từ con lai giữa gà trống Ri với gà mái Lương Phượng, gà có sức đề kháng cao, ít bệnh tật, thời gian tăng trưởng ngắn, thịt thơm ngon phù hợp với nhu cầu sử dụng của người tiêu dùng. Để đem lại hiệu quả cao trong chăn nuôi đòi hỏi phải có kỹ thuật thật tốt từ khâu vệ sinh chuồng trại, chọn con giống cho đến công tác chăm sóc nuôi dưỡng và phòng trị bệnh.

\section{Vật liệu, phương pháp nghiên cứu}

\subsection{Vật liệu nghiên cứu}

Nghiên cứu trên gà Ri Lai (trống Ri x mái Lương Phượng) nuôi thả vườn.

\subsection{Phuơng pháp nghiên cúu và các chỉ tiêu} theo dõ $i$

2.2.1. Phuong pháp theo dõi, thu thập thông tin

- Cập nhật thông tin thông qua sổ sách của trại 
- Trực tiếp thực hiện đầy đủ qui trình chăm sóc, nuôi dưỡng đàn gà

- Hàng tuần cân gà vào sáng sớm trước khi cho ăn. Cân mẫu từ 3 - $5 \%$ tối thiểu 50 con trước khi cân quây dồn gà vào và bắt ngẫu nhiên cân từng con tính giá trị trung bình (Trần Thanh Vân, 2015) [4].
- Quan sát trực tiếp đàn gà hằng ngày

- Theo dõi tình hình mắc bệnh để kịp thời xử lý và điều trị bệnh. Theo dõi, ghi chép số liệu chính xác.

\subsubsection{Các chỉ tiêu theo dõi}

* Tỷ lệ nuôi sống của gà qua các tuần tuổi

* Khả năng sinh trưởng của gà

$$
\text { Tỷ lệ nuôi sống }(\%)=\frac{\sum \text { số gà cuối kỳ (con) }}{\sum \text { số gà đầu kỳ }(\operatorname{con})} \times 100
$$

Sinh trưởng tích lũy $(\mathrm{g} / \mathrm{con})$ : Cân gà trước khi đưa gà vào thí nghiệm, sau đó tiến hành cân gà hàng tuần vào buổi sáng thứ 5 trước khi cho ăn.

* Theo dõi tình hình mắc bệnh của gà

$$
\text { Tỷ lệ nhiễm bệnh }(\%)=\frac{\sum \text { số gà nhiễm bệnh (con) }}{\sum \text { số gà theo dõi (con) }} \times 100
$$

\subsection{Phuơng pháp xủ̉ lý số liệu}

Các số liệu thu thập được xử lý theo phần mềm Microsoft Office Excel.

\section{Kết quả và thảo luận}

\subsection{Công tác phòng bệnh cho gà}

\subsubsection{Công tác vệ sinh phòng bệnh}

Việc vệ sinh chuồng trại và môi trường xung quanh trang trại là việc làm cần thiết và thường xuyên để ngăn chặn hạn chế những tác động xấu nhất từ môi trường bên trong cũng như bên ngoài chuồng nuôi.

Bảng 3.1. Lịch vệ sinh sát trùng chuồng trại

\begin{tabular}{|c|c|c|}
\hline Nội dung công việc & Số lần thực hiện (lần/tuần) & Tổng số lần thực hiện trong 6 tháng \\
\hline Vệ sinh quét dọn chuồng trại & 7 & 168 \\
\hline Vệ sinh máng ăn, máng uống & 14 & 168 \\
\hline Sát trùng trước khi vào trại & 7 & 20 \\
\hline Đảo trấu, thêm trấu & 1 & 22 \\
\hline Phun sát trùng định kỳ xung quanh \\
chuồng trại
\end{tabular}

Công tác vệ sinh phòng bệnh cho gà có vai trò quan trọng quyết định đến sự thành công hay thất bại của chăn nuôi gà. Nếu thực hiện tốt công tác phòng bệnh cho gà sẽ hạn chế dịch bệnh xảy ra và lây lan, đồng thời quyết định thành công của chăn nuôi gà (Lê Văn Năm, 2004) [2].

3.1.2. Phòng bệnh bằng vắc xin
Trong quá trình chăn nuôi thường xuyên tiêm phòng vắc xin cho đàn gia cầm chủ động để đảm bảo an toàn dịch bệnh. Trước khi sử dụng vắc xin không pha thuốc kháng sinh vào nước uống trong 12 giờ, pha vắcxin phải đúng theo tỷ lệ quy định. Lịch phòng và sử dụng các loại vắc xin cho đàn gà như sau: 


\begin{tabular}{|c|c|c|c|c|c|}
\hline $\begin{array}{r}\text { Ngày } \\
\text { tuổi }\end{array}$ & Loại vắc xin & Phòng bệnh & $\begin{array}{c}\text { Cách dùng và liều } \\
\text { lượng }\end{array}$ & $\begin{array}{c}\text { Tổng số gà được tiêm } \\
\text { phòng (con) }\end{array}$ & \begin{tabular}{|} 
Độ an \\
toàn $(\%)$
\end{tabular} \\
\hline 3 & Livacox-T & Cầu trùng & \begin{tabular}{|r} 
Nhỏ miệng \\
1 giọt
\end{tabular} & 1196 & 100 \\
\hline 5 & $\begin{array}{c}\text { Gumboro } \\
228 \mathrm{E}\end{array}$ & Gumboro & \begin{tabular}{|r} 
Nhỏ miệng \\
1 giọt
\end{tabular} & 1193 & 100 \\
\hline 7 & $\begin{array}{l}\text { - Lasota } \\
\text { - Đậu gà }\end{array}$ & $\begin{array}{l}\text { - Newcastle } \\
\text { - Đậu gà }\end{array}$ & \begin{tabular}{|r} 
- Nhỏ mắt \\
1 giọt \\
- Chủng cánh
\end{tabular} & 1193 & 100 \\
\hline 14 & $\begin{array}{c}\text { Gumboro } \\
228 \mathrm{E}\end{array}$ & Gumboro & Nhỏ miệng & 1178 & 100 \\
\hline 18 & $\begin{array}{l}\text { - Lasota } \\
\text { - Đậu gà }\end{array}$ & $\begin{array}{l}\text { - Newcastle } \\
\text { - Đậu gà }\end{array}$ & $\begin{array}{l}\text { - Nhỏ mắt } \\
\text { - Chủng cánh }\end{array}$ & 1176 & 100 \\
\hline 24 & ILT & $\begin{array}{l}\text { Viêm thanh khí quản } \\
\text { truyền nhiễm }\end{array}$ & $\begin{array}{c}\text { Pha ILT } \\
\text { với nước sạch }\end{array}$ & 1175 & 100 \\
\hline 42 & Clone 45 & Newcastle & $\begin{array}{c}\text { Tiêm dưới da cố } \\
0.25 \mathrm{ml}\end{array}$ & 1159 & 100 \\
\hline
\end{tabular}

Việc phòng bệnh cho gà bằng vắc-xin đã diễn ra thuận lợi an toàn tuyệt đối (tỉ lệ đậ $100 \%$ qua các

lần). Trong tổng số các đợt phòng bệnh thì không có con gà nào bị phản ứng phụ với vắc xin, và làm chết gà.

Bảng 3.3. Tỷ lệ nuôi sống của đàn gà Ri lai

\begin{tabular}{|c|c|c|c|}
\hline Tuần tuổi & $\begin{array}{c}\text { Số lượng gà đầu kỳ } \\
(\mathbf{c o n})\end{array}$ & $\begin{array}{c}\text { Số lượng gà chết } \\
\text { (con) }\end{array}$ & Tỷ lệ nuôi sống trong tuần (\%) \\
\hline Sơ sinh & 1200 & 0 & 100 \\
\hline 1 & 1193 & 7 & 99,41 \\
\hline 2 & 1178 & 15 & 98,72 \\
\hline 3 & 1176 & 2 & 99,83 \\
\hline 4 & 1174 & 2 & 99,83 \\
\hline 5 & 1162 & 12 & 98,96 \\
\hline 6 & 1159 & 3 & 99,74 \\
\hline 7 & 1155 & 4 & 99,65 \\
\hline 8 & 1144 & 11 & 99,03 \\
\hline 9 & 1138 & 6 & 99,47 \\
\hline
\end{tabular}




\begin{tabular}{|c|c|c|c|}
\hline Tuần tuổi & $\begin{array}{c}\text { Số lượng gà đầu kỳ } \\
\text { (con) }\end{array}$ & $\begin{array}{c}\text { Số lượng gà chết } \\
\text { (con) }\end{array}$ & Tỷ lệ nuôi sống trong tuần (\%) \\
\hline 10 & 1135 & 3 & 99,73 \\
\hline 11 & 1134 & 1 & 99,91 \\
\hline 12 & 1132 & 2 & 99,82 \\
\hline 13 & 1132 & 0 & 100,00 \\
\hline 14 & 1130 & 2 & 99,82 \\
\hline 15 & 1129 & 1 & 99,91 \\
\hline
\end{tabular}

Qua thực tế chăn nuôi cho thấy tỷ lệ chết ở gà thấp cao nhất là $1,28 \%$. Tỷ lệ nuôi sống của các đàn gà thí nghiệm giai đoạn 10 - 15 tuần tuổi cao hơn so với giai đoạn 0 - 9 tuần tuổi. Sự chênh lệch này là do ở giai đoạn đầu, gà chưa hoàn thiện các bộ phận và chức năng của cơ thể, chịu sự tác động lớn bởi môi trường bên ngoài. Giai đoạn 10 - 15 tuần tuổi, tuy ăn hạn chế nhưng cơ thể gà đã phát triển đầy đủ các bộ phận, đặc biệt lông vũ đã thay thế cho lông tơ nên ít bị ảnh hưởng hơn bởi các yếu tố môi trường bên ngoài, do đó tỷ lệ nuôi sống cao hơn so với giai đoạn trước.

\subsubsection{Khả năng sinh truởng của gà}

Sinh trưởng tích lũy hay khả năng tăng khối lượng của cơ thể qua các tuần tuổi là một chỉ tiêu vô cùng quan trọng được các nhà chọn giống quan tâm. Trong chăn nuôi gia cầm hướng thịt thì đây là chỉ tiêu để xác định năng suất thịt của đàn gà, đồng thời cũng là biểu hiện khả năng sử dụng thức ăn của đàn gà qua các thời kỳ sinh trưởng của chúng.

Bảng 3. 4. Sinh truởng tích lũy của gà qua các tuần tuổi ( $g r)$

\begin{tabular}{|c|c|c|}
\hline \multirow{2}{*}{ Tuần tuổi } & \multicolumn{2}{|c|}{ Gà Ri lai } \\
\cline { 2 - 3 } & $\mathrm{X} \pm m_{x}$ & $\mathrm{CV}(\%)$ \\
\hline Sơ sinh & $33,03 \pm 0,40$ & 8,10 \\
\hline 1 & $94,57 \pm 2,60$ & 15,00 \\
\hline 2 & $132,77 \pm 3,00$ & 12,40 \\
\hline 3 & $223,87 \pm 6,10$ & 15,00 \\
\hline 4 & $312 \pm 14,00$ & 24,60 \\
\hline 5 & $386,67 \pm 13,80$ & 19,60 \\
\hline 6 & $463,33 \pm 12,20$ & 14,40 \\
\hline 7 & $561,33 \pm 15,00$ & 14,60 \\
\hline 8 & $746,67 \pm 20,00$ & 14,70 \\
\hline 9 & $927 \pm 28,70$ & 17,00 \\
\hline 10 & $1059,67 \pm 52,20$ & 27,00 \\
\hline 11 & $1229,33 \pm 38,40$ & 17,10 \\
\hline 12 & $1364,33 \pm 43,40$ & 17,40 \\
\hline 13 & $1468,67 \pm 46,60$ & 17,40 \\
\hline 14 & $1636,33 \pm 55,10$ & 18,40 \\
\hline 15 & $1807,67 \pm 63,10$ & 19,10 \\
\hline & & \\
\hline & & \\
\hline & & \\
\hline
\end{tabular}


Bảng 3.4 cho thấy, khối lượng cơ thể gà tăng dần theo tuần tuổi, phù hợp với quy luật sinh trưởng và phát triển chung của gia cầm. Tuy nhiên khả năng sinh trưởng là không đều nhau ở mỗi giai đoạn. Khối lượng cơ thể gà Ri Lai lúc sơ sinh là $33,03 \mathrm{~g} / \mathrm{con}$; lúc 3 tuần tuổi là $223,87 \mathrm{~g} / \mathrm{con}$, ở tuần tuổi thứ 15 gà có khối lượng 1807,62g/con. Kết quả trong nghiên cứu này cũng tương đương với các tác giả Hồ Xuân Tùng (2008) [4], khối lượng cơ thể lúc 1 ngày tuổi trên các tổ hợp gà lai $\mathrm{F} 1$ (Ri $\mathrm{x}$ Lương Phượng) là 36,6 gam, lúc 3 tuần tuổi là $227,77 \mathrm{~g}$, ở tuần tuổi thứ 15 gà có khối lượng $1897,12 \mathrm{~g} /$ con. Hệ số biến dị dao động từ 8,10 $27 \%$, sở dĩ biên độ dao động lớn là gà được nuôi chung trống mái mà con trống có khả năng sinh trưởng nhanh hơn con mái.

3.2.3. Sinh truởng tuyệt đối và tuơng đối của gà Ri lai

Bảng 3.5. Sinh truởng tuyệt đối, tương đối của gà Ri Lai

\begin{tabular}{|c|c|c|}
\hline Tuần tuổi & Sinh trưởng tuyệt đối (g/con/ngày) & $\begin{array}{l}\text { Sinh trưởng tương đối } \\
(\%)\end{array}$ \\
\hline $0-1$ & 8,7 & 85,71 \\
\hline $1-2$ & 5,4 & 46,62 \\
\hline $2-3$ & 13 & 51,09 \\
\hline $3-4$ & 12,5 & 32,89 \\
\hline $4-5$ & 10,6 & 21,37 \\
\hline $5-6$ & 10,9 & 18,04 \\
\hline $6-7$ & 14,00 & 19,13 \\
\hline $7-8$ & 26,4 & 30,92 \\
\hline $8-9$ & 25,7 & 20,00 \\
\hline $9-10$ & 18,9 & 21,24 \\
\hline $10-11$ & 24,2 & 13,63 \\
\hline $11-12$ & 19,2 & 9,66 \\
\hline $12-13$ & 14,9 & 7,51 \\
\hline $13-14$ & 23,9 & 7,19 \\
\hline $14-15$ & 24,4 & 6,36 \\
\hline Trung bình & 16,90 & 26,09 \\
\hline
\end{tabular}

Qua bảng 3.5 cho thấy sinh trưởng tuyệt đối của gà ở tăng dần theo tuần tuổi và đạt giá trị cao nhất vào lúc 7 tuần tuổi sau đó giảm dần. Giá trị tăng khối lượng tuyệt đối đạt cao nhất là 26,40 ( $\mathrm{g} /$ con/ngày). Kết thúc 15 tuần tuổi sinh trưởng tuyệt đối là 24,40 ( $\mathrm{g} / \mathrm{con} / \mathrm{ngày})$. Trung bình cả giai đoạn là 16,90 (g/con/ngày).
Qua kết quả sinh trưởng tương đối ở bảng 3.5 cũng cho thấy tốc độ sinh trưởng tương của gà tuân theo quy luật sinh trưởng của gia cầm. Sinh trưởng tương đối của ở tuần 1 là cao nhất đạt $85,71 \%$ giảm dần còn $6,36 \%$ ở tuần tuổi thứ 15 .

3.2.4. Khả năng thu nhận và chuyển hóa thức ăn của đàn gà Ri Lai 
Bảng 3.6. Khả năng thu nhận và chuyển hóa thức ăn của gà Ri Lai

\begin{tabular}{|c|c|c|c|}
\hline Tuần tuổi & $\begin{array}{l}\text { Thu nhận thức } \\
\text { ăn (g/con/ngày) }\end{array}$ & $\begin{array}{l}\text { Tiêu tốn thức ăn/kg tăng } \\
\text { khối lượng trong tuần (kg) }\end{array}$ & $\begin{array}{l}\text { Tiêu tốn thức ăn/kg tăng khối } \\
\text { lượng cộng dồn (kg) }\end{array}$ \\
\hline $0-1$ & 9,50 & 1,34 & 1,34 \\
\hline $1-2$ & 12,50 & 1,74 & 1,54 \\
\hline $2-3$ & 25,60 & 1,97 & 1,75 \\
\hline $3-4$ & 31,50 & 2,50 & 1,98 \\
\hline $4-5$ & 35,80 & 3,36 & 2,27 \\
\hline $5-6$ & 40,20 & 3,67 & 2,52 \\
\hline $6-7$ & 52,60 & 3,76 & 2,75 \\
\hline $7-8$ & 72,60 & 2,47 & 2,67 \\
\hline $8-9$ & 72,20 & 2,97 & 2,73 \\
\hline $9-10$ & 80,50 & 2,53 & 2,69 \\
\hline $10-11$ & 85,50 & 3,53 & 2,80 \\
\hline $11-12$ & 85,50 & 4,43 & 2,95 \\
\hline $12-13$ & 95,20 & 5,83 & 3,17 \\
\hline $13-14$ & 100,20 & 5,96 & 3,36 \\
\hline $14-15$ & 100,50 & 6,32 & 3,55 \\
\hline
\end{tabular}

Số liệu bảng 3.6 cho thấy khả năng thu nhận thức ăn của gà tăng dần qua các tuần tuổi, phù hợp với khối lượng gà tại từng thời điểm. Ở tuần thứ nhất khả năng thu nhận thức ăn của gà là 9,5 (g/con/ngày) tăng lên 100,50 (g/con/ngày) ở tuần tuổi thứ 15 .

Tiêu tốn thức ăn/kg tăng khối lượng của gà cũng tăng dần qua các tuần tuổi. Chi phí thức ăn $/ \mathrm{kg}$ tăng khối lượng trong tuần thấp nhất ở tuần đầu với giá trị $1,34 \mathrm{~kg}$, tăng lên $6,32 \mathrm{~kg}$ ở tuần tuổi thứ 15 . Điều này hoàn toàn phù hợp với khối lượng gà ở từng thời điểm cụ thể.

Tiêu tốn thức ăn/kg tăng khối lượng cộng dồn của gà cũng tăng dần qua các tuần tuổi. Kết thúc tuần thứ 15 chi phí thức ăn/kg tăng khối lượng của gà là $3,55 \mathrm{~kg}$.

Từ số liệu trên cho thấy khi nuôi gà Ri lai thương phẩm nên xuất bán sớm khi khối lượng, chất lượng được thịt trường chấp nhận, càng xuất bán sớm sẽ càng đưa lại hiệu quả kinh tế cho người chăn nuôi.

\subsection{Kết quả điều trị bệnh trên gà}

\subsubsection{Tình hình mắc bệnh trên đàn gà thịt}

Trong quá trình chăm sóc nuôi, dưỡng tại trại. Khi theo dõi đàn gà phát hiện những con có những biểu triệu chứng của bệnh sẽ tiến hành nhặt ra một ô riêng để chẩn đoán và điều trị.

Bảng 3.7. Một số bệnh thường gặp ở gà Ri lai

\begin{tabular}{|c|c|c|c|}
\hline Tên bệnh & $\begin{array}{c}\text { Tổng số gà theo } \\
\text { dõi (con) }\end{array}$ & $\begin{array}{c}\text { Số gà có triệu chứng } \\
\text { bệnh (con) }\end{array}$ & $\begin{array}{c}\text { Tỷ lệ } \\
(\%)\end{array}$ \\
\hline Bệnh tiêu chảy do E.coli & 1193 & 13 & 1,08 \\
\hline Bệnh CRD & 1174 & 16 & 1,36 \\
\hline Bệnh Cầu trùng & 1155 & 20 & 1,73 \\
\hline
\end{tabular}


Qua bảng 3.7 cho thấy tình hình mắc bệnh ở đàn gà của trại tuy đã có công tác phòng bệnh tuy nhiên vẫn có nhiều bệnh sảy ra. Đặc biệt bệnh cầu trùng chiếm tỷ lệ cao nhất là $1,73 \%$ do trời mưa nhiều thay đổi thời tiết gà dễ mắc bệnh; tiếp đó là bệnh CRD chiếm $1,36 \%$ và cuối cùng đến bệnh tiêu chảy do E.coli chiếm 1,08\%. Theo Phạm Sỹ Lăng, Tô
Long Thành (2006) [1], bệnh cầu trùng gà là bệnh rất phổ biến và được xem là một trong những bệnh gây tác hại lớn trong chăn nuôi.

\subsubsection{Sủ dụng thuốc trong điều trị bệnh cho gà}

Khi đàn gà có biểu hiện về bệnh cần tiến hành xử lí kịp thời nhanh chóng tránh tình trạng bùng phát thành dịch gây thiệt hại về kinh tế.

Bảng 3.8. Kết quả điều trị bệnh gà mắc các bệnh

\begin{tabular}{|c|c|c|c|c|c|c|c|}
\hline STT & Tên bệnh & $\begin{array}{c}\text { Số gà điều } \\
\text { trị } \\
\text { (con) }\end{array}$ & Tên thuốc điều trị & Cách dùng & $\begin{array}{c}\text { Anời gian } \\
\text { điều trị } \\
\text { (ngày) }\end{array}$ & $\begin{array}{c}\text { Số gà } \\
\text { chết } \\
\text { (con) }\end{array}$ & $\begin{array}{c}\text { Tỳ lệ an } \\
\text { toàn }(\%)\end{array}$ \\
\hline 1 & $\begin{array}{c}\text { Tiêu chảy } \\
\text { do } E . c o l i\end{array}$ & 1193 & Vn.coliamox $50 \%$ & Cho uống & 5 & 8 & 99,64 \\
\hline 2 & Cầu trùng & 1155 & Coxymax & $\begin{array}{r}\text { Cho uống 3 ngày nghì } \\
2 \text { ngày, rồi cho uống 2 } \\
\text { ngày }\end{array}$ & 5 & 11 & 99,73 \\
\hline 3 & CRD & 1174 & Doxy+tilmicosin & Trộn vào thức ăn & 5 & 10 & 99,71 \\
\hline
\end{tabular}

Thực tế cho ta thấy: Tuy nuôi môi trường nuôi khép kín lúc nhỏ và bán chăn thả lúc gà được một tháng tuổi trở lên và được nuôi dưỡng chăm sóc tốt, nhưng vẫn không thể tránh được sự ảnh hưởng của xấu từ điều kiện môi trường.

Trong quá trình điều trị, nhờ chẩn đoán bệnh chính xác và điều trị kịp thời nên kết quả điều trị bệnh trên đàn gà đạt kết quả tốt. Sau 2 đến 3 ngày điều trị, đàn gà có những chuyển biến tích cực. Ăn, uống vận động dần trở lại bình thường. Sau 5 ngày, hầu hết biểu hiện của bệnh trên đàn gà không đáng kể.

Việc phát hiện sớm và sử dụng thuốc có hiệu quả trong điều trị khi gà nhiễm bệnh cho kết quả tốt. Trong chăn nuôi việc phòng và trị bệnh cho đàn gà là rất quan trọng.

\section{Kết luận}

Tỷ lệ nuôi sống của đàn gà tại trại tỷ lệ nuôi sống qua các tuần tuổi của gà Ri Lai khá cao thấp nhất là $98,96 \%$ cao nhất là $100 \%$. Khả năng sinh trưởng tuyệt đối trung bình cả giai đoạn là 16,90 (g/con/ngày), sinh trưởng tương đối là 26,09 (g/con/ngày). Tình hình gà mắc bệnh ở trại bệnh cầu trùng, bệnh $\mathrm{CRD}$, bệnh tiêu chảy do E.coli. Sau 5 ngày được điều trị gà có những biểu hiện tích cực.

\section{REFERENCES}

[1] Lang, P. S., Thanh, T. L. (2006). Parasitic protozoa in domesstic. Hanoi Agricultural Publishing House, 138 - 142, Vietnam.

[2] Nam, L. V. (2004). Treatment guidelines for complex grafting diseases in chickens. Hanoi Agricultural Publishing House, Vietnam.

[3] Tung, H. X. (2008). Research on cross breeding Luong Phuong Hoa and Ri chichens to select and breed free - range chickens for farming. Doctoral thesis in agricultural. Viet Nam Academy of Science and Technology, Vietnam

[4] Van, T T., Hoan, N. D., My, N. T. T. (2015). Curriculum on poultry farming. Hanoi Agricultural Publishing House, 234, Vietnam.

[5] Livestock resources in Viet Nam (2020). Livestock situation in the whole country in December 2019, Vietnam. 